\section{Physical examination in psychiatry}

DeAR SIRS

Dr Hughes' account of the physical examination in psychiatry raises some interesting issues (Psychiatric Bulletin 1991, 15, 615-616). Clearly, in-patients should receive a comprehensive physical examination where this is appropriate. A superficial examination may in some cases cause the team to believe there is no organic pathology and falsely reassure the patient.

Consultant interest and supervision of junior staff are essential to maintain standards. Post-graduate training in psychiatry places little emphasis on physical examination skills. The Membership Examination of the Royal College of Psychiatrists may include a relevant physical examination in the clinical section. The Membership Examination of the Royal Australian and New Zealand College of Psychiatrists always includes a general examination in medicine and may involve an external examiner who is a physician. Apart from the College placing greater emphasis on such skills, a weekly visit by a neurology registrar or senior registrar to the ward round would enhance communication between the disciplines. In addition this would provide access to a physician interested in the interface with psychiatry and remind psychiatrists of the value of retaining their medical diagnostic skills.

Middlesex Hospital

VIVIENNE SCHNIEDEN

Wolfson Building

London WIN 8AA

\section{Achieving a Balance - Establishing a new Regional Scheme for Psychiatric Registrars}

DeAR SiRS

We read the account of the new regional scheme for South East Thames with interest (Herzberg \& Watson, 1991). The same pressures have led to a very similar solution here so that Oxford has started a regional training scheme for registrars taking in all the previous district schemes. There are many points of similarity. It is essential that the registrar contracts remain with and are administered by regions and this is happening.

The scheme is organised by a Regional Coordinating Tutor who chairs a committee of Speciality Tutors from each district, a university representative, a junior representative and the Tutor for Overseas (Visiting) Registrars. For the time being we have retained in addition the original Speciality Training Committee which consists of all of the above with other representatives and chaired by the
Regional Adviser. This is partly to give a wider perspective when needed and also to provide an arbiter if a problem cannot be resolved between the tutors. It was decided that the Regional Co-ordinating Tutor should be a clinician and not an administrator, should have been a Psychiatric Tutor and should not be the Regional Adviser.

The appointment of the Regional Co-ordinating Tutor is by the Postgraduate Dean on the recommendation of the Speciality Training Committee after consultation with the Professor.

We would agree that a budget is essential and are preparing one for presentation to the Director of Postgraduate Education.

A point of difference is that we expect registrars to spend on average two years in the grade although flexibility is possible for particular educational needs. This is because we anticipate the present bottle neck at appointment to senior registrar moving down to appointment to registrar level, with the result that trainees are likely to spend considerably longer at SHO level. For trainees to spend one year in a peripheral hospital and one year in a teaching district needs an equal number of posts between the teaching and non-teaching districts.

This has been achieved by the interchange of some registrar and SHO posts between the districts. This does not alter the manpower figures for the region as a whole. Care needs to be taken to ensure that SHO training in each district is not adversely affected.

It does occur to us that if career trainees come to spend more time at SHO level, and there continues to be pressure for GP trainees to have experience in psychiatry, and if overseas trainees require some experience at SHO level before becoming visiting registrars, then there may not be enough SHO places to satisfy the demand. The JPAC calculations may not have taken this into account.

The welfare of trainees moving between districts will need to be carefully monitored; moving house or increased travel can place a considerable burden on trainees and their families. It will be necessary to have good accommodation and good support from personnel officers.

P. D. MADDOCKS

Wrexham Park Hospital

CATHERINE P. OPPENHEIMER

Wrexham, Slough

SL2 4HL

\section{Reference}

Herzberg, J. L. \& Watson, J. P. (1991) Achieving a balance: establishing a new regional scheme for psychiatric registrars in South East Thames. Psychiatric Bulletin 15, 552-554. 